\title{
Abandono de tratamento: itinerários terapêuticos de pacientes com HIV/Aids
}

\author{
Abandonment of treatment: therapeutic itineraries of HIV/Aids \\ patients
}

Marilza Rodrigues', Ivia Maksud²

RESUMO A pesquisa objetiva compreender o 'abandono de tratamento' - situações de descontinuidade do medicamento e/ou ruptura de vínculos entre pacientes, profissionais e serviço de saúde. Buscou-se compreender como pacientes de uma unidade básica de saúde percebem e significam a experiência em questão e como o serviço de saúde a enfrenta. A partir da literatura das ciências sociais em saúde, foram elaborados quatro eixos de análise. Os dados apontam lacunas nas ações de saúde e fragilidade dos profissionais em lidar com situações de vulnerabilidade. Recomenda-se aos gestores e serviços, portanto, a qualificação da equipe profissional e a atividade de 'busca ativa' aos pacientes considerados faltosos.

PALAVRAS-CHAVE HIV. Síndrome da Imunodeficiência Adquirida. Terapêutica. Serviços de saúde. Adesão à medicação.

ABSTRACT The objective of this research is to understand the 'abandonment of treatment' - situations of discontinuation of medication and/or of breaking of bonds between patients, professionals, and health services. It aims to understand how patients from a basic health care unit see and signify this experience and how health care service faces it. Based on Social Sciences literature on Health, four axes of analysis were developed. The data shows gaps in health actions and the fragility of professionals in dealing with situations of vulnerability. Therefore, the qualification of the professional staff and actions for the 'active search' of missing patients are advisable.

KEYWORDS HIV. Acquired Immunodeficiency Syndrome. Therapeutics. Health services. Medication adherence.

1 Prefeitura do Rio de Janeiro, Secretaria Municipal de Saúde do Rio de Janeiro - Rio de Janeiro (RJ), Brasil.

marilzaecr@hotmail.com

2 Fundação Oswaldo Cruz (Fiocruz), Instituto Nacional de Saúde da Mulher, da Criança e do Adolescente Fernandes Figueira (IFF) - Rio de Janeiro (RJ), Brasil. iviamaksud@gmail.com 


\section{Introdução}

Ao longo das últimas décadas, apesar de significativas mudanças ocorridas no tratamento do Vírus da Imunodeficiência Humana/Acquired Immunodeficiency Syndrome (HIV/Aids) no Brasil, como a oferta universal da medicação antirretroviral, a disponibilização de exames sofisticados pelo Sistema Único de Saúde (SUS) e direitos a benefícios sociais, não é incomum que pacientes, em algum momento do seu percurso terapêutico, passem pela experiência do 'abandono de tratamento'.

Em 2009, o Ministério da Saúde sugeria como critérios para 'abandono de tratamento' casos em que pacientes não comparecessem ao serviço por três meses após retirar seus medicamentos ou que não comparecessem às consultas em um intervalo maior do que seis meses. Os manuais programáticos ressaltam que, para melhor prognóstico do tratamento, é necessária a adesão rigorosa aos antirretrovirais, tendo em vista que a irregularidade na tomada do medicamento ou seu abandono aumenta a "probabilidade da replicação do HIV, bem como a disseminação de vírus multirresistente" (COSTA; MORAES; OLIVEIRA, 2014, P. 677). Apesar de esforços como esses, as razões que motivam o abandono em si são complexas e variadas.

Entender o que se configura como uma 'não adesão' ou 'abandono', acionando a literatura das ciências humanas em saúde, é a proposta deste artigo, que busca compreender como 'pacientes' percebem e significam a experiência do abandono de tratamento e como o serviço de saúde se organiza para enfrentá-lo. A definição de abandono adotada para esta discussão abarca tanto a interrupção da ingestão do medicamento antirretroviral por parte dos pacientes como seu afastamento do acompanhamento ambulatorial (exames, consultas e orientações da equipe profissional).

A escolha da literatura sobre itinerários terapêuticos como suporte teórico pareceu adequada como analisador de trajetórias do cuidado para a saúde. Ela ajudou a interpretar os dados e a compreender as necessidades de saúde colocadas em jogo: a quem e como os sujeitos recorrem para ter resolutividade em suas demandas e de quais recursos dispõem para concretizar seu direito à saúde (ALVES; SOUZA, 1999; GERHARDT, 2009; HELMAN, 2009; BELLATO ET AL., 2011).

Estudos prévios que tentaram compreender os motivos para a descontinuidade do tratamento para controle do HIV/Aids chamam atenção para diversos aspectos, sugerindo que esse é um tema complexo para ser reduzido a uma visão monolítica. Cardoso e Arruda (2005), por exemplo, consideram que o diagnóstico do HIV/Aids repercute de diversas maneiras de acordo com os inúmeros acontecimentos que fazem parte da trajetória do paciente. Também, situações de tensões e dilemas particulares podem contribuir para a descontinuidade do tratamento. Conforme esses autores mostraram, algumas das razões pelas quais os pacientes decidirão sobre o abandono ou não do tratamento estão ligadas a fatores como 'esquema terapêutico', 'momento da evolução da doença', 'grau de apoio familiar' e as próprias representações sociais que a soropositividade tem para esses sujeitos.

Alguns estudos consideram que algum grau de não aderência em qualquer tratamento é universal e ocorre tanto em países ricos como em países pobres (NEMES; JORDAN, 2000; PAULILO; NARCISO, 2001). Além disso, a literatura revela que o período inicial do tratamento tende a ser a fase mais vulnerável para que ocorra abandono. Se, por um lado, os efeitos colaterais dos antirretrovirais são fatores mais comuns encontrados na literatura, por outro, também é possível explorar os frágeis vínculos das pessoas com os serviços de saúde. Nemes et al. (2009) sugerem, por exemplo, que a adesão ao tratamento tende a ser menor quando o serviço se apresenta desorganizado e quando os pacientes faltam muitas vezes às suas consultas (NEMES; JORDAN, 2000). Vem sendo discutida e reforçada por 
vários autores a importância de implementar estratégias que facilitem o diálogo entre profissionais e entre profissionais e pacientes. Essa iniciativa tem-se colocado como oportunidade de construção de vínculo e confiança, aspectos fundamentais nas intervenções de adesão ao tratamento HIV/Aids (SILVA ET AL., 2015; CARDOSO; ARRUDA, 2005).

\section{Metodologia}

A pesquisa foi realizada em uma unidade básica de saúde do SUS no município do Rio de Janeiro. O serviço de saúde foi escolhido por pertencer à rede pública, estar situado em local de fácil acesso, desenvolver programas com propostas para o cuidado integral em saúde e atividades integradas de pesquisa, ensino ou extensão nas universidades. Quanto aos critérios para a escolha dos sujeitos de pesquisa, pretendeu-se abordar pacientes com HIV/Aids que não mais compareciam às consultas médicas, realizavam exames ou acessavam medicamentos. Foram incluídos entre os sujeitos de pesquisa profissionais de saúde em exercício de suas atividades funcionais.

O projeto de pesquisa foi submetido a dois comitês de ética em pesquisa: ao Comitê de Ética em Pesquisa da Universidade Federal Fluminense, sob o ${ }^{\circ} 12383$, sendo aprovado em 17 de abril de 2013; e ao Comitê de Ética em Pesquisa da Secretaria Municipal de Saúde e Defesa Civil - RJ, sob o n ${ }^{0} 12 / 12$, sendo aprovado em 29 de junho de 2012.

O trabalho de campo ocorreu entre os meses de julho e dezembro de 2012 e conteve observação participante, registros em diário de campo, conversas informais e entrevistas, estas últimas gravadas e transcritas para posterior análise. Com exceção de duas, as entrevistas foram realizadas no próprio serviço de saúde. O nome da instituição foi omitido, e foram atribuídos nomes fictícios aos interlocutores para preservar suas identidades. A referida pesquisa não contou com suporte financeiro.
Para realizar a análise dos dados, utilizaram-se as sugestões de autores que trabalham com análise de conteúdo em sua modalidade temática, e originalmente também beneficiou-se da construção gráfica do itinerário terapêutico dos pacientes entrevistados (POPE; MAYS, 2009; MINAYO, 2008). Para sistematizar os dados, realizaram-se leitura e releitura do material de campo e retomaram-se as hipóteses e objetivos iniciais da pesquisa. Identificou-se um conjunto de informações que foram organizados a partir dos seguintes eixos: 1) Entrar no serviço de saúde; 2) Estar no serviço de saúde; 3) Deixar o serviço de saúde e 4) Retornar ao serviço de saúde. Realizaram-se interpretações e correlações com os referenciais teóricos e com a bibliografia levantada.

\section{O campo de pesquisa}

As primeiras impressões sobre o local da pesquisa decorreram de uma postura de atenção tanto ao que as pessoas faziam assim como o que diziam (BECKER, 2007). Dessa forma, aproximou-se da pessoa que se constituiria na principal informante da pesquisa: uma médica pediatra designada pela direção do serviço até a chegada da médica infectologista responsável pelo atendimento dos pacientes com HIV/Aids que viria a ser, posteriormente, mais uma interlocutora.

$\mathrm{O}$ atendimento aos pacientes que vivem com HIV/Aids no serviço acessado teve início no ano de 1994, quando era realizado por um médico clínico e, eventualmente, por um pneumologista. Em 1997, um infectologista foi designado para o serviço, assumindo a coordenação do programa de Aids. Com o aumento da demanda de atendimentos, outra infectologista foi contratada, assumindo a coordenação do programa, em 2001, após a saída do primeiro infectologista.

A chamada 'porta de entrada' do serviço (ou seja, como as pessoas chegam até a unidade antes de se tornarem pacientes) se dá por meio da 'estratégia de acolhimento', 
conjunto de exercícios e práticas profissionais pautados em recomendações e diretrizes estabelecidas nas atuais políticas de saúde que visam atender o paciente de 'modo humanizado' e com 'resolutividade'. Em dois turnos (manhã/tarde), pacientes que se dirigem ao serviço são direcionados por equipe responsável para os respectivos setores para atendimento de suas demandas. A unidade de saúde atualmente é caracterizada por ser uma unidade mista onde convivem o Programa de Saúde da Família, com sua equipe de agentes comunitários, e posto de saúde tradicional.

O caminho para localizar os entrevistados que serão apresentados a seguir foi percorrido a partir de levantamento no livro de matrícula dos pacientes que haviam desistido do tratamento: para o serviço em questão, aqueles que não comparecem a nenhuma consulta com infectologista por período de seis meses são considerados 'em abandono do tratamento', e seus prontuários são retirados do arquivo e transferidos para caixas que são acondicionadas em local determinado pela administração do serviço.

Naquele período, a referida caixa estava alocada em espaço desativado destinado à guarda de materiais com defeito, objetos fora de uso, além de prontuários de outros programas da instituição. No momento inicial da pesquisa, as chaves estavam desaparecidas por uma semana, mostrando-se um lugar de difícil acesso. A realização da pesquisa contribuiu para que fosse aberta pela primeira vez a caixa na qual foram depositados os prontuários de pacientes do programa do HIV/Aids 'que estavam em abandono'. Esse cenário mostrou que as informações sobre pacientes em abandono do tratamento não foram tampouco digitalizadas em meio eletrônico. De posse do livro, identificaram-se vários pacientes que se afastaram da unidade de tratamento por tempo superior a seis meses. Ao lado de seus nomes, constava a palavra 'abandono' e o período de afastamento do serviço. Nem todas os espaços estavam preenchidos: faltavam dados como endereço e/ou nome de genitora, bairro e data de nascimento. Ao longo da pesquisa, observou-se que os espaços em branco gradualmente iam sendo complementados pela profissional de saúde que ajudava a levantar informações nos prontuários dos pacientes. Interessava recuperar, sobretudo, seu endereço, telefone e data do abandono, ou seja, o registro da última vez que os pacientes haviam comparecido ao serviço.

Houve outras dificuldades para acessar pacientes com HIV/Aids que abandonaram o serviço: informações desatualizadas (o paciente muda endereço e/ou o número do telefone e não comunica a alteração ao serviço; o paciente não possui em seu prontuário registro de telefone por não ter a linha telefônica ou se recusa a informar o número da linha; o telefone registrado no serviço apresenta defeito ou está fora de área ou caixa postal no momento da tentativa de contato; preenchimento incorreto dos prontuários pelos profissionais de saúde - número de telefone ou endereço incompletos). Alguns prontuários continham informações até mesmo equivocadas: registro de abandono quando o paciente foi a óbito ou registro de óbito quando o paciente foi transferido para outro serviço de saúde.

Diante da imprecisão acerca das informações fornecidas, constatou-se o quão difícil é, para o serviço de saúde, dimensionar a situação de abandono de tratamento dos pacientes com HIV/Aids.

O local de pesquisa foi frequentado mais amiúde pela pesquisadora principal, tomando parte na vida daquele lugar: observando pessoas, circulando pelos corredores, lendo avisos e cartazes nos murais, mantendo-se atenta às entrelinhas de conversas entre pacientes que aguardavam atendimento na sala de espera, participando dos eventos e atividades do serviço etc. Essa iniciativa possibilitou a convivência mais informal com várias pessoas e o conhecimento de particularidades sobre aquele serviço que 
certamente em outras condições não brotariam com tanta espontaneidade.

Essa convivência possibilitou o agendamento das entrevistas com os profissionais de saúde. A nutricionista foi a primeira profissional acessada. Mais adiante, abordaram-se, nesta ordem: a infectologista, a farmacêutica e o enfermeiro, que exercia o cargo de gestor. Do contato com a infectologista, foi possível pensar estratégias variadas para acessar os pacientes. Aqueles que porventura procurassem o serviço para retornar ao tratamento, após contato de rotina com a infectologista, também seriam direcionados à pesquisadora. Dessa combinação de estratégias, com maior fluidez, contataram-se, com sucesso, pacientes com HIV/Aids que passaram pela experiência de abandonar o medicamento, equipe profissional e o serviço de saúde.

\section{Resultados e discussão}

\section{Os interlocutores}

Todos os pacientes entrevistados - três mulheres e cinco homens - confirmaram ter experimentado alguma forma de abandono do tratamento. Possuíam idade superior a 18 anos. Apenas um possuía diagnóstico de HIV recente, correspondente a um período inferior a um ano. Cinco pacientes não tinham indicação para uso do antirretroviral, e três relataram que antes de abandonarem o tratamento faziam uso desse tipo de medicação. No período em que estiveram afastados do tratamento, os sujeitos foram acometidos por doenças oportunistas e decidiram buscar ajuda com infectologista, retornando ao uso regular da medicação.

Um paciente possuía curso superior completo, dois possuíam ensino médio, quatro possuíam ensino fundamental e um paciente não forneceu este dado. Um paciente estava aposentado por invalidez, quatro tinham vinculo empregatícios e três não trabalhavam. Uma paciente declarou-se evangélica; e três, católicos. Não foi possível classificar as práticas religiosas dos demais pacientes. Dos profissionais de saúde entrevistados, um homem e três mulheres tinham idades entre 45 anos e 60 anos, sendo dois de cor branca, um negro e um pardo. Dois profissionais consideravam-se agnósticos, um kardecista e um não informou. Em relação à escolaridade, dois possuíam nível superior completo e dois cursaram pós-graduação. Quanto à formação e tempo de experiência com HIV/Aids, os dados variaram: enfermeiro, médica, nutricionista e farmacêutica, com experiência de 7 a 26 anos na atenção ao HIV/Aids.

\section{Entrando no serviço de saúde}

$\mathrm{O}$ acesso ao sistema de saúde dos pacientes entrevistados apresentou singulares trajetórias marcadas por momentos vivenciados com mais ou menos dificuldades em busca de cuidados de saúde a partir do resultado positivo para o HIV/Aids. Alguns entrevistados, mesmo se sentindo em uma situação de exposição ao HIV/Aids, protelaram buscar o serviço de saúde para testar-se quanto ao estado sorológico para o HIV. Outros buscaram o serviço de saúde por se perceberem com sintomas que indicavam mudança no seu estado de saúde; outros procuram o serviço por terem estabelecido relação sexual com pessoa sabidamente soropositiva ou por desconfiança do parceiro estar infectado com HIV/Aids. Em muitos casos, a parcialidade das informações contribuiu para retardar o diagnóstico do HIV/Aids e precipitar a condição de adoecimento.

Tais dados corroboram o que se encontrou na literatura. Para Bellato et al. (2011), a condição crônica transita por diferentes temporalidades, com períodos de agudização e silenciamento da doença. Os períodos de agudização são marcados, em geral, por um ritmo acelerado de busca por cuidados dentro e fora do sistema de saúde. 
Apenas dois pacientes acessaram o centro de saúde mais próximo ao local em que residiam. Os demais utilizaram o serviço de urgência/emergência de hospitais públicos ou privados e o Centro de Testagem e Aconselhamento (CTA). Além disso, os dados confirmam pesquisas anteriores que mostram que a rede básica de serviços de saúde não tem conseguido absorver em primeiro plano as pessoas que se descobrem soropositivas. Dos oito pacientes entrevistados, apenas dois relataram acessar o centro de saúde próximo ao local que residiam no intuito de ter o diagnóstico de sua situação de saúde. Os demais utilizaram os serviços de urgência/emergência dos hospitais públicos ou privados ou CTAs.

O conjunto de entrevistas mostrou que o acesso ao serviço para o atendimento das necessidades do paciente não se dá somente pelo fluxo institucionalizado no âmbito do SUS. Em concordância com Cohn et al. (1991), a presente pesquisa mostrou que a população estrutura suas próprias estratégias de acesso aos serviços a partir do conhecimento e da percepção para identificar suas necessidades. Ao reconhecer que a insuficiência do modelo de atenção em vigência pode ser superada com manobras que podem ajudá-lo a ter acesso a terapêuticas e ações que julga importantes para o seu cuidado, o paciente acaba por definir um caminho próprio para tentar resolver sua demanda. Diante dos obstáculos para acessar de fato o serviço para serem atendidos em suas necessidades de saúde, os próprios pacientes tentam contorná-los valendo-se da sua percepção para, à sua maneira, conquistar o direito à saúde: "Eu procurei uma pessoa conhecida que trabalhava na recepção do posto de saúde imediatamente abri prontuário e passei pela doutora" (Rosa, paciente soropositiva desde 1997, afastou-se do tratamento por seis meses, retornando adoecida de herpes zoster).

No exemplo acima, a paciente, ao se valer do conhecimento pessoal com profissional de saúde, conseguiu garantir imediatamente seu acesso ao serviço e ações de saúde, sem cumprir as exigências do protocolo de entrada no serviço de saúde que costumeiramente é cobrado dos demais pacientes que buscam cuidados de saúde no SUS.

Ao conseguirem acessar os serviços de saúde, os interlocutores se depararam com protocolos e rotinas rígidas que, segundo Mattos (2008), frequentemente desconsideram as demandas trazidas pelos pacientes. Os profissionais de saúde, por sua vez, também não conseguem escutar e apreender o contexto de vida dos pacientes de modo a identificar outras necessidades de saúde, limitando-se a focar pontualmente e de modo fragmentado suas queixas. Mesmo após a entrada no sistema, os sujeitos relataram, então, várias dificuldades para marcar consultas, exames de rotina, exames mais complexos e consultas com especialistas.

No percurso em busca de cuidados de saúde, os entrevistados não só usaram a rede de serviços do SUS, mas também buscaram o apoio em outras redes de atenção, como a religião e o saber popular. Loyola (1983) já havia identificado que a filiação religiosa pode se imiscuir às práticas terapêuticas. Neste estudo, chegou-se a conclusões aproximadas, isto é, os pacientes demonstraram em seus itinerários que recorriam concomitantemente ao médico e às orações.

\section{Estando no serviço de saúde}

Foi possível constatar, tanto por meio dos relatos sobre as experiências dos pacientes como dos profissionais de saúde, o reconhecimento de uma política de enfrentamento da epidemia que tem ampliado o acesso de pacientes a diversos tipos de serviços, desde o básico, como o atendimento médico, exames, medicamentos específicos, até os recursos de alta complexidade, como exame de genotipagem. Por outro lado, uma política de desinvestimento tem trazido limitações aos pacientes entrevistados, como, por exemplo, demora dos resultados de exames 
de rotina, falta de leitos para internação e remédios para doenças oportunistas e efeitos colaterais. A garantia do acesso aos medicamentos encontra seus entraves no cotidiano da gestão, como se pode ver na interpretação de um profissional de saúde/gestor entrevistado:

A gente tem que lembrar que é um coquetel, e eu tenho que ter no mínimo três e no máximo cinco drogas para dispensar. Não adianta ter o paciente que utiliza cinco drogas e eu só tenho três drogas no almoxarifado, às vezes eu tenho uma determinada droga para seis meses, porém a que eu preciso hoje eu não tenho nem para um mês. (Antonio, gestor e profissional de saúde).

Em busca de remédios, exames, consultas, leitos para internação e outros recursos, o paciente segue construindo seu itinerário terapêutico. Os relatos apresentados comportam caminhos próprios em busca de cuidados de saúde. A continuidade do tratamento ambulatorial é marcada pelo ritual das visitas regulares do paciente ao seu médico assistente. No serviço investigado, todos os pacientes com HIV/Aids são atendidos por uma única infectologista. Ao final de cada consulta, os pacientes são reagendados a cada três meses. No caso de ocorrer intercorrência em relação ao tratamento do HIV/Aids, antes do período agendado, o paciente poderá se dirigir à infectologista solicitando atendimento extra. De modo geral, durante cada consulta, espera-se que o paciente tenha oportunidade de expor questões que julga importante em relação ao seu tratamento de saúde; e do médico se espera que esteja preparado para ouvir o paciente, no sentido mais amplo, de modo a atender às suas necessidades. Na prática, essas expectativas nem sempre se realizam, e episódios de frustração foram relatados pelos pacientes: medo, vergonha e culpa foram sentimentos expostos pela maioria desses pacientes que não encontraram brechas no espaço terapêutico para discutir suas questões com os profissionais de saúde. A atitude acolhedora da equipe profissional é importante para alavancar mudança no comportamento do paciente ante o adoecimento. Estudos confirmam "a dificuldade de alguns profissionais para escutar e valorizar a demanda do paciente" (SILVA ET AL., 2015 P. 221). Na pesquisa realizada, pode-se ver o relato abaixo nessa mesma direção.

Fui encaminhada para fazer cirurgia e não comuniquei ao médico que era portadora do HIV, mesmo com a imunidade baixa. Tinha medo de contar, pois já havia sido discriminada, então optei a não revelar; eu precisava do tratamento. (Joana, soropositiva desde 1999, abandonou o tratamento por seis anos, retornou após realizar cirurgia e ter complicações devido à baixa imunidade).

Os itinerários dos pacientes mostram várias histórias de insatisfação com o atendimento dos profissionais de saúde e, em especial, dos médicos.

Escutar a bronca da doutora é duro; um homem do meu tamanho esculachado. Sai arrasado. Você tem problema por todo lado, em casa, com a família, aí você não volta [...] abandona. (Raul, 38 anos, afastado do tratamento há um ano. Agendou consulta, mas não retornou ao tratamento no período da pesquisa).

É razoável supor que a tensão gerada nesse encontro contribua para que o paciente não consiga argumentar ou minta ao profissional a respeito de sua insatisfação com a atenção recebida. Na maioria das vezes, o paciente se afasta do serviço e abandona o tratamento sem ao menos informar ao médico. Essa foi a decisão também tomada por Raul. Por outro lado, os profissionais de saúde, por vezes, também são vistos como aliados frágeis perante a estrutura do serviço, como pode ser visto em relatos tanto de pacientes quanto de gestores: "O sistema não dá suporte à doutora" (Omar, 32 anos, abandonou o tratamento por 
duas vezes, no dia da entrevista agendou nova consulta de retorno).

O capital intelectual que a gente tem é muito fragilizado ainda, a gente tem muitas dificuldades porque a maioria dos profissionais que estão dentro das nossas unidades têm o nível fundamental e ficam o dia inteiro dispensando medicamento. Então essa multidão de drogas, que eles não trabalham só com Aids, eles trabalham com todas as outras doencas, isso traz uma certa confusão. Se o profissional não sabe qual o remédio que está dentro da geladeira dele para orientar ao paciente, fica muito mais difícil. (Antonio, gestor e profissional de saúde).

Bonet (2004) mostrou que mesmo que haja um esforço dos profissionais em se preocupar com o paciente, é mais comum que sigam o modelo da biomedicina que tem como foco a doença. De forma parecida, Santos (2007) observou o imperativo do cuidado do vírus. Na pesquisa realizada, também se observou que a solicitação de exames e diagnóstico de doenças suplanta a compreensão do modo de vida do paciente, o significado de suas experiências de vida e o contexto do seu tratamento. Para alguns profissionais de saúde ouvidos na pesquisa, essa discussão sobre o cuidado ofertado pelos profissionais de saúde aos pacientes levanta um ponto importante: a fragilidade da formação acadêmica, sinalizada inclusive pelos próprios médicos. Silva et al. (2015) sugerem aos pacientes e equipe profissional que encontrem nos serviços de saúde espaços de acolhimento, tendo em vista que a relação paciente e equipe profissional é um processo relacional e deve considerar suas subjetividades. Nesse sentido, o cuidado deveria considerar o paciente como um todo, sem focar apenas o cuidado do vírus HIV, como também mostrou Santos (2007).

Durante a pesquisa, o medicamento antirretroviral foi mencionado com destaque tanto pelos pacientes que a utilizavam como por aqueles que não tinham indicação para uso. Apesar do reconhecimento de sua potência, os pacientes entrevistados expressaram inúmeras dificuldades em relação aos seus efeitos colaterais diante do uso prolongado, bem como medo do agravamento da doença. Considerando as diretrizes de tratamento médico disponibilizadas pelo Ministério da Saúde à época da pesquisa, nem todos os pacientes infectados pelo vírus HIV precisavam usar medicação, mas precisariam ser acompanhados regularmente por meio de consultas e exames. Observa-se que, em geral, os esforços dos pacientes para a busca por serviços de saúde e/ou cuidados profissionais se apresentaram de modo mais esporádico nesse período dito 'assintomático'. Os pacientes não compareciam às consultas e nem realizavam exames de rotina com frequência porque 'se sentiam bem'.

$O$ recebimento da prescrição para o uso do medicamento antirretroviral costuma ser um momento crítico para os sujeitos. Há nesse momento necessidade de reorganização do cotidiano, gerenciamento da tomada dos remédios obedecendo a horários, doses certas, preocupação com o sigilo, efeitos colaterais do medicamento e outras. Essas mudanças dialogam com um quadro maior de referência, que situa os sujeitos em termos de pertencimento social, estilo de vida e capital simbólico. A nova informação implica a assimilação de uma nova condição, um novo saber sobre si que para alguns dos informantes significou a confirmação da condição de doente de Aids e morte eminente, mesmo sem apresentar sintomas (MAKSUD, 2009). O medo dos pacientes vivenciarem situações de preconceito e discriminação leva alguns a silenciarem diante das famílias e amigos sobre qualquer circunstância que envolva o seu tratamento. O tratamento do HIV/Aids pode gerar modelos explicativos distintos para um e outro grupo. Nem sempre pacientes e profissionais de saúde partilham das mesmas crenças e concepções em relação à doença e ao tratamento, de tal forma que se alcance uma relação de negociação. 


\section{Deixando o serviço de saúde}

O abandono do tratamento, embora seja prática recorrente, não é um assunto muito discutido entre os profissionais de saúde. No cotidiano, os profissionais produzem informações (prontuários, banco de dados para controle do acesso ao medicamento antirretroviral, consulta) que poderiam ajudar a discussão sobre esse tema e alavancar propostas de intervenção. Todavia a variedade de informações produzida acaba subutilizada: um ou outro profissional tenta se aproximar do tema por intermédio de iniciativas incipientes, revelando mais um esforço pessoal do que uma estratégia do serviço.

De forma geral, os relatos dos pacientes entrevistados convergem para uma questão importante: a inexistência de proposta sistematizada para acolher pacientes com má adesão ao tratamento e prevenção do abandono.

A decisão de abandonar o tratamento parece ter sido difícil para os entrevistados. Todos, sem exceção, não discutiram com familiares, amigos e conhecidos, tampouco com o médico, sua decisão de abandonar o tratamento. Temiam ser pressionados para retornarem ao tratamento: "Mentia. A família e os amigos perguntavam se eu apanhava os remédios, respondia que sim, mas tinha abandonado" (Leonardo, 49 anos, soropositivo desde 2005 , abandonou o tratamento no mês de outubro/2011, retornando em setembro/2012 após dois meses internado no Hospital Miguel Couto).

Por outro lado, a perspectiva de ter sua doença conhecida publicamente expõe o paciente ao medo de ser discriminado e sofrer preconceito, e, consequentemente, os leva a buscar estratégias para as interações cotidianas, como mostram Silva et al. (2015). Os variados relatos dos entrevistados mostraram outros fatores que contribuem para o abandono do tratamento, a partir de suas lentes, tais como: falta de apoio emocional e financeiro das famílias, a não aceitação da doença Aids, efeitos colaterais dos antirretrovirais, a quantidade de comprimidos ingeridos diariamente, a periodicidade das consultas, o estigma da doença Aids, o medo da morte, depressão e influência de más amizades. Ademais, ao contrário do que as orientações médicas poderiam supor, há, segundo os entrevistados, benefícios para aqueles que decidiram suspender seu tratamento.

Essa sumida me faz um pouco esquecer. Vir fazer exame, lembra que sou soropositivo, lembra que vou ficar doente. O abandono pode não fazer bem fisiologicamente, mais psicologicamente, faz. (Irlan, 31 anos, abandonou o tratamento por diversas vezes ao longo de oito anos).

Durante o período de abandono do tratamento, Irlan e outros entrevistados dedicaram parte do tempo na tentativa de reaproximação dos familiares, investiram na troca de emprego, na prática de atividade física e outros. Percebe-se que as situações descritas passam longe do cenário de uma pessoa adoecida. Essa constatação também foi encontrada no trabalho de Gonçalves et al. (1999) sobre adesão à terapêutica da tuberculose (TB) em Pelotas (RS). Os autores mostram que o 'papel' desempenhado na maior parte da vida dos indivíduos que abandonaram o tratamento para TB não foi o de 'doente'.

Nos percursos relatados pelos entrevistados durante o período de abandono do tratamento, foram raros os momentos em que estes externaram necessidades de saúde que precisaram de intervenção do profissional de saúde. Nos casos em que isso ocorreu, foram situações pontuais que o próprio paciente resolveu com cuidados do seu próprio repertório.

\section{Retornando ao serviço de saúde}

Os dados evidenciaram que a iniciativa de fazer contato com paciente em abandono do tratamento por telefone ou mesmo por aerograma para saber notícias e estimular seu retorno não tem sido uma prática dos profissionais do serviço pesquisado. A 'busca de 
faltosos' é uma estratégia recomendada pelo Ministério da Saúde, no entanto nenhum dos informantes da pesquisa recebeu contato do serviço dessa natureza. Somente uma paciente que na época havia abandonado também o tratamento de Tuberculose (TB) foi procurada pelo serviço. É importante destacar que, no serviço de saúde pesquisado, o tratamento de TB é o único programa que tem orientação diferenciada no tocante à busca de pacientes em abandono: um profissional é designado para monitoramento do programa, acionando o agente de saúde para contatar os pacientes faltosos. O estudo realizado por Silva et al. (2015) sobre comorbidade TB/HIV faz referência à importância atribuída pelos pacientes ao apoio recebido do serviço de saúde. Nesse sentido, quando a paciente entrevistada lembra do chamado para retorno ao serviço/tratamento, fica também evidenciado seu reconhecimento pelas ações realizadas pela equipe de saúde.

O ambulatório de HIV/Aids onde os pacientes eram atendidos antes de abandonarem o tratamento é o local procurado em caso de decisão de retorno aos cuidados de saúde. Quando se dá, este retorno passa, paradoxalmente, pelo processo de agravamento do seu quadro de saúde. Todos os oito pacientes da pesquisa retornaram adoecidos ao serviço de saúde buscando agendar consulta para tratamento (sete pacientes compareceram à consulta agendada). Como a maioria das entrevistas para a pesquisa ocorreu no próprio ambulatório, foi possível observar um certo sentimento de ansiedade dos pacientes para o encontro com a médica infectologista.

Observou-se que o reencontro dos pacientes que haviam abandonado o tratamento com a infectologista - após a decisão de retomá-lo - era carregado de tensão. Todos os pacientes tinham em mente que 'levariam uma bronca' da profissional de saúde por terem se ausentado do tratamento.

Eu nunca levei o tratamento a sério. Às vezes não acredito, eu até queria fazer novo exame. Quando se está bem, come, trabalha tem disposição você não tá nem aí, é difícil pensar. Para a médica, ela só fala que tem que tomar remédio. Comecei tomar o remédio da Aids e o da tuberculose. No início foi difícil, tomava oito comprimidos, depois foi diminuindo, fiquei com quatro. À medida que melhorava, comecei por minha conta a diminuir a quantidade e depois tinha dia que esquecia mesmo. Distraía com o trabalho, e a hora do remédio passava. Parei com o remédio e não voltei para consulta. No fundo a gente sabe que o vírus que está dentro da gente é uma bomba relógio. Voltei, é a segunda vez que abandono e volto. Fico com medo. Eu sei que a qualquer hora a gente pode adoecer, ter que ficar internado e morrer. A pressão está dentro da gente, isso atormenta e não diz respeito a ninguém, somente a mim. (Leonardo, paciente em abandono do tratamento pela segunda vez há 10 meses).

$\mathrm{Na}$ fala de Leonardo, reconhecem-se elementos que dão significado à sua experiência de estar soropositivo e que constituem sinal de alerta para o profissional de saúde investir em estratégias para prevenir a descontinuidade do tratamento (CARDOSO; ARRUDA, 2005). A fala da infectologista revela sua reação diante dos pacientes considerados em situação de abandono do tratamento pelo serviço e confirma a preocupação dos pacientes entrevistados:

Quem morre de medo de mim, é porque tá devendo. Todos eles ficam com o rabinho entre as pernas, porque os que abandonaram o tratamento são aqueles que mais levaram broncas. Eles têm tratamento e não querem. Tem hora que sou muito dura, tem hora que eu esculacho. (Dora, médica infectologista).

Essa postura da profissional de saúde, contudo, era entendida de diferentes formas pelos pacientes. Para alguns, pareceu pouco amistosa, afirmando a pouca escuta da infectologista para o que pensa e sente o paciente. Para outros, significava empenho em diagnosticar e tratar o mal-estar que lhes afligia. 
Considerando a subjetividade das pessoas e a complexidade do vivenciar o HIV/Aids, os sentimentos que afloram tanto nos pacientes como nos profissionais de saúde muitas vezes determinam a forma de agir e reagir às situações. É dessa forma que a postura austera da infectologista é rechaçada por alguns pacientes enquanto para outros, sua 'bronca' é entendida como preocupação e cuidado com o paciente que não cumpre sua responsabilidade com o tratamento.

No decorrer dos itinerários terapêuticos dos pacientes, é possível afirmar que as pessoas tomam suas decisões e criam formas próprias para administrar os riscos. Em várias narrativas, constataram-se pacientes por conta própria diminuírem a dosagem da medicação prescrita, faltar à consulta e não realizar exames solicitados, entre outras estratégias. Os estudos sobre adesão ao tratamento do HIV/Aids sinalizam vários obstáculos, como: contradições, distanciamento e negação do paciente em aceitar o diagnóstico de HIV/Aids (SILVA ET AL., 2015).

O retorno ao serviço após o período do abandono é marcado por histórias que trazem a percepção dos informantes sobre o viver com HIV em diferentes espaços da vida e diferentes formas de lidar com as situações que foram sendo apresentadas ao longo do percurso. Observando por essa perspectiva, a fala de Leonardo é exemplar e ajuda a inferir que em suas idas e vindas construiu um vínculo frágil com seu tratamento, mas de certa forma vem aprendendo a monitorar-se quando avalia que estar bem é manter-se bem-disposto e trabalhando. Cabe evidenciar que Leonardo foi o único informante que se manteve em abandono do tratamento até o momento que se esteve no campo de pesquisa. A compreensão sobre sua doença e sobre o tratamento se revela na analogia que faz entre a previsão do tempo e as condições de saúde: "a senhora quando está um dia bonito, com sol, a senhora se preocupa em carregar guarda-chuva? Claro que não, não vai chover!" (Leonardo, paciente em abandono do tratamento pela segunda vez há 10 meses).
Por outro lado, os profissionais de saúde desse serviço também mostram suas fragilidades quando reconhecem que sua formação acadêmica não prepara para as situações complexas que envolvem o cuidar do paciente com HIV/Aids. Além disso, questões associadas à gestão também são pontuadas pelos profissionais: agenda lotada, falta de tempo, estrutura deficiente com número reduzido de consultórios, pouco espaço, ventilação inadequada, número de profissionais insuficiente etc. são exemplos acionados como justificativa para gerenciar situações de crise, limitando-se a 'apagar incêndio'. Nesse sentido, o cuidado ao paciente que retorna após o abandono passa por essas representações, como pode-se ver abaixo.

Interfere principalmente quando o paciente é antigo que você já tem uma relação. Você fica preocupada. Interfere porque depois ele volta doente, a maioria não volta bem, só quando está doente, porque está doente. Então, atendimento sem hora marcada, urgência, preocupação. Não tem local para internação, se você precisar. Não tem para onde encaminhar. Eu tenho que dar conta da emergência aqui dentro. A rede não me dá amparo para fazer internação num serviço adequado. Então isso me estressa, me estressa demais. (Dora, Médica Infectologista).

Algumas dificuldades sinalizadas no cotidiano profissional se constituíram em obstáculos vivenciados na trajetória dos pacientes, no entanto estes, ao decidirem retornar ao tratamento, de algum modo, buscaram reconstituir seu vínculo com o tratamento médico e com o serviço de saúde. Nesse contexto, parece que as circunstâncias e as necessidades do paciente vão direcionando seu engajamento novamente ao serviço, retomando e criando novos vínculos com a equipe profissional. A literatura disponível sobre a temática evidencia um esforço do 'paciente não aderente ao tratamento' para se adaptar às exigências da condição soropositiva, porém, esse esforço nem sempre 
é bem-sucedido. Portanto, como mostram Cardoso e Arruda (2004), ao oscilar períodos de adesão e não adesão, esses pacientes denunciam o modo instável e provisório, bem como os desafios, da rotina de um tratamento para o HIV/Aids (CARDOSO; ARRUDA, 2005).

\section{Conclusões}

O conceito de itinerário terapêutico contribuiu para evidenciar uma série de lacunas do serviço de saúde que parecem dificultar a oferta de um cuidado integral. Possibilitou ainda apreender dados que mostram como os pacientes vivem e convivem com HIV/Aids em seu cotidiano, a quem e como recorrem para ter resolutividade em suas demandas, e de quais recursos dispõem para concretizar o seu direito à saúde. As experiências descritas confirmam a complexidade do tema abandono do tratamento e a necessidade de sistematizar cuidados de saúde tanto nas práticas terapêuticas dos profissionais como no percurso terapêutico percorrido pelos pacientes.

Os resultados da pesquisa chamam atenção para a importância da valorização do protagonismo do paciente no tratamento. Quando estimulados a falar acerca de suas expectativas em relação ao atendimento ofertado no serviço de saúde, muitos aspectos relacionados com os novos hábitos adquiridos no período de abandono do tratamento, como prática de exercício físico e mudança de emprego, vieram à tona. A análise dessas informações e dados revelam que a valorização de práticas de autocuidado é um ponto a ser sublinhado. Por outro lado, não se conseguiu visualizar na fala dos entrevistados referências sobre engajamento social e político visando influenciar a qualidade da atenção nos serviços de saúde. Assim, entende-se que as críticas direcionadas à equipe de saúde e ao serviço se constituíram apenas como desabafo dos pacientes. É possível também pensar a fragilidade dos profissionais de saúde diante do reconhecimento de tais limitações e desafios. O ambulatório de HIV/Aids é um espaço de atendimento contínuo e prolongado, e, por esse motivo, ao lidarem no cotidiano com as circunstâncias ligadas ao viver com HIV/Aids, os profissionais de saúde podem ser levados a situações de desgaste emocional e adoecimento.

Ao considerar todos esses aspectos, e para superar possíveis desafios, recomenda-se aos gestores e serviços, portanto, especial atenção no que concerne à qualificação da equipe profissional em dois pontos: 1) especificidades no cuidado aos pacientes considerados mais vulneráveis e 2) atividades gerenciais de 'busca ativa' dos serviços aos pacientes considerados faltosos.

Conclui-se, por fim, que a construção desse fato - o 'abandono do tratamento' -, tal como apreendido pela pesquisa, extrapola sobremaneira as diretrizes preconizadas pelos documentos oficiais acerca da 'falta de adesão'.

\section{Colaboradores}

Marilza Rodrigues realizou a pesquisa, analisou os dados e redigiu o artigo. Ivia Maksud orientou a pesquisa e redigiu o artigo. 


\section{Referências}

ALVES, P. C. B; SOUZA, I. M. (Org.). Escolha e avaliação de tratamento para problemas de saúde: considerações sobre o itinerário terapêutico. Rio de Janeiro: Fiocruz, 1999.

BECKER, H. S. Segredos e truques da pesquisa. Rio de Janeiro: Zahar, 2007.

BELLATO, R. et al. Itinerários terapêuticos de famílias e redes para o cuidado na condição crônica: alguns pressupostos. In: PINHEIRO, R.; MARTINS, P. H. (Org.). Avaliação em saúde na perspectiva do usuário: abordagem multicêntrica. Rio de Janeiro: CEPESC; Recife: UFPE; São Paulo: ABRASCO, 2011. p. 187-214.

BONET, O. Saber e sentir: uma etnografia da aprendizagem da biomedicina. Rio de Janeiro: Fiocruz, 2004.

CARDOSO, G. C. P.; ARRUDA, A. As representações sociais da soropositividade e sua relação com a observância terapêutica. Ciência \& Saúde Coletiva, Rio de Janeiro, v. 10, n. 1, p. 151-62, jan./mar., 2005.

COHN, A. et al. A saúde como direito e como serviço. São Paulo: Cortez, 1991.

COSTA, S. F. G.; MORAES, D. C. A.; OLIVEIRA, R. C. Adesão de homens vivendo com HIV/AIDS ao tratamento antirretroviral. Escola Anna Nery, Rio de Janeiro, v. 18, n. 4, p. 676-681, out./dez. 2014.

GERHARDT, T. E. Itinerários terapêuticos e suas múltiplas dimensões: desafios para a prática da integralidade e do cuidado como valor. In: PINHEIRO, R; MATTOS, R. A. (Org.). Razões públicas para a integralidade em saúde: $\mathrm{O}$ cuidado como valor. Rio de Janeiro: IMS/UERJ; CEPESC; São Paulo: Abrasco, 2009. p. 279-300.

GONÇALVES, H. et al. Adesão à terapêutica da tuberculose em Pelotas, Rio Grande do Sul: na perspectiva do paciente. Cadernos de Saúde Pública, Rio de Janeiro, v. 15, n. 4, p. 777-787, out./dez. 1999.

HELMAN, C. G. Cultura, saúde e doença. Porto Alegre: Artmed, 2009.
LOYOLA, M. A. Médicos e curandeiros: conflito social e saúde. Rio de Janeiro: Difel, 1983.

MAKSUD, I. O discurso da prevenção da Aids frente às lógicas sexuais de casais sorodiscordantes: sobre normas e práticas. Physis, Rio de Janeiro, v. 19, n. 2, p. 349-369, 2009.

MATTOS, R. A. Cuidado prudente para uma vida decente. In: MATTOS, R. A; PINHEIRO, R. (Org.) Cuidado: as fronteiras da integralidade. Rio de Janeiro: IMS/UERJ; São Paulo: Abrasco, 2008. p. 121- 134.

MINAYO, M. C. S. O desafio do conhecimento: pesquisa qualitativa em saúde. São Paulo: Hucitec, 2008.

NEMES, M. B. et al. Adesão ao tratamento, acesso e qualidade da assistência em Aids no Brasil. Revista da Associação Médica Brasileira, São Paulo, v. 55, n. 2, p. 207-212, 2009.

NEMES, M. B.; JORDAN, M. S. Aderência ao tratamento anti-retroviral em AIDS: revisão da literatura médica. In: TEIXEIRA, P. R.; PAIVA, V.; SHIMMA, E. (Org.). Tá dificil de engolir? Experiência da adesão ao tratamento anti-retroviral em São Paulo. São Paulo: Nepaids, 2000.

PAULILO, M. A. S.; NARCISO, A. M. S. Adesão e AIDS: alguns fatores intervenientes. Serviço Social em Revista, Londrina, v. 4, n. 1, p 27-43, jul./dez., 2001.

POPE, C. M., MAYS, N. Pesquisa qualitativa na atenção à saúde. Porto Alegre: Artmed, 2009.

SANTOS, D. F. A assistência às pessoas vivendo com HIV/AIDS: aprendendo a cuidar do vírus ou da pessoa. 2007. 216 f. Tese (Doutorado em Saúde Coletiva) Instituto de Medicina Social, Universidade do Estado do Rio de Janeiro, Rio de Janeiro, 2007.

SILVA, J. B. et al. Os significados da comorbidade para os pacientes vivendo com TB/HIV: repercussões no tratamento Physis, Rio de Janeiro, v. 25, n. 1, p. 209-229, jan./mar. 2015.

Recebido para publicação em dezembro de 2016

Versão final em maio de 2017

Conflito de interesses: inexistente

Suporte financeiro: não houve 